\title{
Leaving Engineering: Gender Differences
}

\author{
Harriet Hartman, Moshe Hartman \\ Rowan University/Ben-Gurion University
}

\begin{abstract}
The paper focuses on retention in an innovative undergraduate engineering program with many "female-friendly" features despite its design as best practices for all students. Both male and female "stayers" in the program are compared to "leavers" on a variety of characteristics, including pre-college and family background, grades, satisfaction with the Rowan program, engineering self-confidence, and future expectations about their engineering major and career. Data come from a special 2000-1 survey of all Rowan engineering students.
\end{abstract}

Introduction

Student retention in engineering is problematic. Estimates of the loss in undergraduate students who begin engineering and either switch to another major or drop out altogether range from $40 \%$ to $70 \%$ (depending on who is considered a beginning student in engineering and what institution is considered). ${ }^{1,2,16,21}$ This low rate of retention is not unique to engineering students: as Astin \& Astin $^{2}$ and Adelman ${ }^{1}$ show, students completing the major they start out with average approximately $42 \%$. What does characterize engineering in particular is the gender gap in completion rate nationally. The retention rate of female engineering students is consistently about 20 percentage points or more below that of males ${ }^{1}$, even when the female students have as high or higher academic achievements as males.

Studies of why students migrate out of engineering have identified several factors at work. They include both "push" factors out of engineering (including poor academic performance, inadequate preparation, unwillingness to work) and "pull" factors attracting students into another major (summarized in Seymour \& Hewitt ${ }^{21}$ ). However, of more relevance to the present project, some of the reasons for switching out of engineering pertain to the very pedagogy with which engineering is traditionally taught: hard "weeding out" classes rather than a nurturing environment; a lack of social and ethical context surrounding the academic work; a strong emphasis on individual competition; lack of warm and close interpersonal relationships with faculty and peers ${ }^{7,21}$. Astin \& Astin $^{2}$ contribute the insight that interaction with engineering faculty may actually backfire and prove to be negative influences on persistence in the major. Adelman ${ }^{1}$ further refines the insight by showing that compared to students who stay in engineering, students who leave engineering display a higher degree of dissatisfaction with academic and work preparation aspects of their experience. Thus, high achievers may switch out of engineering because of the way it is taught and the interpersonal climate, even though had they continued they might have contributed highly to the field as engineering professionals. Huang \& Peng ${ }^{11}$ reinforce these findings with their conclusions that, relative to men, women in 
science and engineering programs "face difficulties of a largely psychocultural nature" rather than difficulties in terms of preparation, academic achievement, or family support.

The Rowan engineering program provides an interesting setting in which to study this process. Established in 1996, the Engineering College incorporates four disciplines: chemical, civil/environmental, electrical/computer and mechanical engineering. Uniting all disciplines is a common core course required of all students each semester. In this course, "Engineering Clinic", students work in interdisciplinary teams to complete projects that are often contracted from actual corporate settings through a partnership with regional sponsors; project results are presented each semester formally and in professional demeanor. In the junior and senior years, the audience for these reports includes the wider engineering community and corporate sponsors. In addition to the thorough integration of team work and interdisciplinary cooperation into the program, a "hands-on, minds-on" approach integrates the subject matter of the more theoretical courses with the projects being worked on that semester; a "just-in-time" pedagogy insures that the concepts applied in the Clinic projects have just been introduced in other courses, so that the material is still fresh in the students' mind $^{5}$. The sophomore clinic teams with the College of Communication to integrate the teaching of a common core of communication skills to all students. Faculty engage in reflexive pedagogy, continually assessing and revising the program.

In addition to these curricular and pedagogical innovations, the College has a student-to-faculty ratio of approximately 17:1 and class sizes not exceeding 35, facilitating personal student-faculty interaction both within and outside of class The tightly structured curriculum results in strong cohort solidarity among students who take most of their courses together throughout the four year program.

The basic features of the Rowan program directly address a number of the institutional factors cited as diminishing persistence in the engineering field, and are considered cutting edge for undergraduate engineering education. The interdisciplinary teamwork and holistic project experiences, for example, exemplify the kind of learning experience which Rosser ${ }^{18}$ and Margolis \& Fisher ${ }^{13}$ have suggested as necessary to increase the retention of women in science, engineering, and technological fields--and which the 1995 NSF Workshop on Restructuring Engineering Education recommended for all engineering learning environments ${ }^{15}$. The impersonality of traditional engineering school climates is replaced by a strong faculty-student mentoring and advising program, and close interaction between students and faculty in laboratory and research settings at all levels, also recommended as necessary both for general engineering education and to retain female undergraduates in particular ${ }^{21}$. Whether these features help reduce the differentials in retention, or improve retention more generally, has implications for undergraduate engineering programs and perhaps even more broadly, other undergraduate programs.

Reviewing retention rates for the first five years of the program (1996-2001) shows that the average first-year retention rate for female students $(85 \%)$ is actually higher than that of male students $(80 \%)$. Indeed, for every retention rate available (first-year, second-year, third year, etc.), women's retention is the same or higher than men's. The six year graduation rate for the 1996 cohort is the same for men and women (80\%), while the five year graduation rate for the 1997 cohort and the 4-year graduation rate for the 1998 cohort is higher for women than for men (62.5\% for women and $50.8 \%$ for men in the 1997 cohort; $52.9 \%$ for women and $45.6 \%$ for men in the 1998 cohort $)^{9}$. Not only is the traditional gender gap in retention eliminated, but the retention rates themselves are quite high compared to national data: for example, Adelman ${ }^{1}$ finds 
a gender gap in first-year retention and a persistent 20\% gap in completion rates for males and females (males averaging 61.6\%; females, 41.9\%); Astin \& Astin ${ }^{2}$ show that the underrepresentation of women in engineering widens during the undergraduate years (pp. 3-4). Huang \& Peng ${ }^{11}$ find that after five years, $41.2 \%$ of male and $35.7 \%$ of female science \& engineering students had left the field, compared to $31.4 \%$ of Rowan's males and $25.0 \%$ of Rowan's females in the first three cohorts (1996-1998). That the Rowan data show no gender gap or a higher retention rate for women in engineering, for every retention measure (first-year, second-year, graduation in 5 years or 6 years, etc.), suggests the program is indeed female-friendly.

To understand better the way this program is female-friendly, we have been conducting a study of Rowan engineering students, to determine the impact of the program on the traditional gender gap in persistence and satisfaction in engineering. Two surveys are given each year, one at the beginning of the fall semester, and one at the end of the spring semester. The surveys are administered in required classes, reaching almost all of the students. The principal investigator or a research assistant administer the surveys, reinforcing the written notice that the survey is being administered independent of the engineering program itself. Students signed written permission to link their initial surveys to subsequent surveys and other information stored by the University, such as transcripts; while names are collected to be able to link these various sources of information, confidentiality is assured and protected.

In the fall, students are asked about their family background, high school preparation and achievement, support by significant others for their engineering pursuit, preferred learning styles, self-confidence in themselves as students and as engineering students, perception of problems for women and men pursuing scientific, mathematical and engineering careers, their expectations about completing the major at Rowan, financial concerns, and their expectations of what a job in engineering will give them. In the spring, many of the questions are repeated, including their self-confidence in themselves as engineering students, their plans for the future, their perception of problems in the field for women and men, their expectations about jobs; thus, changes in these respects over the course of the year can be measured. In addition, they are asked to evaluate programmatic features such as the engineering clinic, group work, lab work, workload and many other aspects of the program; the interpersonal climate of faculty-student and peer relations; and their satisfaction with the major. In the current research project, to study how the features of Rowan's engineering program are related to retention, survey responses of students who began with a major in engineering but subsequently left engineering for another major ("leavers") were compared to students who began with a major in engineering and stayed in engineering ("stayers").

Being able to use this survey data to compare stayers and leavers is a major advantage over previous studies that have been done in this topic. Huang \& Peng ${ }^{11}$, basing their analysis on the Beginning Postsecondary Students (BPS) Longitudinal Study incorporates a large national sample and are able to relate retention to family, individual, and institutional factors; however, their study combines science and engineering students, and is limited in the individual and institutional factors measured, particularly as pertain to engineering students. Adelman ${ }^{1}$ based his study on a large national sample of student transcripts (High School \& Beyond data), to decipher the paths students take in and out of engineering; however, he used only minimal data on "satisfaction with higher education" and no data on orientations to engineering, specific reactions to program elements, self-confidence, or future plans. Seymour \& Hewitt ${ }^{21}$ interviewed 335 students who were or who had been science, math or engineering majors at 7 different 
institutions. However, they relied on student's recollections for reasons they left their science, math, or engineering majors, without the availability of extensive data collected prior to switching out. While Felder, Felder, Maurney, Hamrin \& Dietz ${ }^{6}$ did do a longitudinal study, their entire sample is 124 students in chemical engineering alone; and limited data are collected from them since the major focus was on reaction to differences in classroom procedures. Goodman et al. ${ }^{8}$ also did a longitudinal study, but their sample, while national, is only of female students; further, because their study was web-based, over $40 \%$ of the sample, especially those who left engineering, chose not to respond to the study.

Therefore, two features position the proposed project to make an important contribution to our understanding of retention: (1) having extensive data collected prior to the students' leaving, for both males and females, including background variables, their reaction to the Rowan program, self-confidence in engineering, their future expectations about their engineering major and career; (2) having both males and females in the sample; and (3) having the uniquely innovative program of Rowan to study.

\section{Research Procedures}

The first part of the project identified those students who started the engineering major at Rowan and were currently enrolled in a different major. This data was provided by Institutional Research, and enabled us to identify those students who had left the major and who had participated in at least one of the earlier surveys administered in the Engineering School before they left the engineering major. Their responses were compared to the students who did not leave the engineering major ("stayers"), to determine whether there were any patterns of differences in terms of family background, high school background, support for engineering by significant others, self-confidence as engineering students, participation in extra-curricular engineering activities, perception of problems in the field of engineering, satisfaction with various facets of the Rowan program and interpersonal climate, expectations about their future in engineering, and academic achievement (overall GPA and GPA in engineering courses). The results of this analysis are presented below.

\section{Results}

\section{1) Retention Among Students who Completed Survey}

In this section we compare those students who stayed in the program through 2002, after taking our survey, to those who left engineering, so that we can relate their retention to characteristics measured in our study. A student was considered to have dropped out of the program (a "leaver") if they formally had changed their major or graduated with a major other than engineering, if they were academically dismissed from the university, or if they had not attended the university for two semesters or more. Students who were officially designated as "stop outs" on the university records were not considered to have dropped out of the program, as they had indicated an official intention to return to the program after a brief break in attendance. If a student had multiple majors, and at least one of them was engineering, they were not considered to have dropped out of the program. All other students still in the engineering program in the spring of 2002 or who graduated earlier as an engineering major were considered "stayers." 
The breakdown of the students who took our survey during the academic year 2000-01 and later dropped out of the engineering program is presented in Table 1 . The majority who dropped were first-year students at the time of the survey. About $25 \%$ who dropped out were sophomores when they took the survey, $12 \%$ juniors, and only $3 \%$ (1 student) seniors. Since most students switch out during the first two years, this distribution is to be expected. However, it does not mean that they necessarily dropped out as first-year students or sophomores; only that when they took our survey they were first-year students or sophomores. Because of the small numbers, we have not broken the "leavers" down by when they left the program.

The "leavers" were fairly evenly distributed between the majors. The slightly lower proportion of leavers who are chemical engineering majors results from there being fewer chemical engineering students who took the survey that year. The slightly lower proportion of students who dropped whose major was "general" is actually somewhat misleading, since this major was available primarily for first-year students and less than $10 \%$ of the entire population of engineering students had this major. Of all students in our survey who had a "general" engineering major, $20 \%$ of them later dropped out, as opposed to $8-11 \%$ of each of the other majors. This is one of the reasons that the "general" major was later eliminated from the program; it functioned as a "catch-all" category for students who were undecided about their specialization and made it more difficult for these students to form connections with other students and faculty in their first year or two.

Of the students who took our survey and later dropped, $27 \%$ were female. Given that women are $20 \%$ of the students in engineering at Rowan, this might be construed as meaning that more women drop out than men. However, this is not the case, as we presented above. The slightly higher percentage of women among those took our survey and later dropped out is because there is a slightly higher representation of the women in the program in our survey than from the male students. The reason for this slightly higher representation is that, because of the smaller numbers of women in the entire program ( 76 females vs. 337 males), greater efforts were made to track female students who were absent from their classes when the survey was administered, and these efforts resulted in $93.4 \%$ of the female engineering students responding to the fall and/or spring survey, while $83.3 \%$ of the male students responded. Compared to other studies, this is a very high response rate, even among the males, and can be considered satisfactorily representative of the engineering student body at the time.

\section{2) Background Characteristics of Stayers vs. Leavers}

In terms of background characteristics, stayers and leavers did not differ significantly in terms of parents' characteristics (Table 2). Nor did they differ significantly in terms of having a sibling in the fields of science, engineering or math, nor in terms of the extent of support from significant others they perceived for their pursuit of engineering (an index of support was created from responses to a series of questions about the opinions of parents, siblings, close friends, influential teachers and high school counselors about the student's pursuit of engineering; more detail can be found in the Appendix).

In terms of pre-college background, stayers and leavers did not differ in terms of how many extra-curricular science/math activities they were involved in during high school, nor in terms of how many math and science AP courses they had, nor in terms of their math SAT score (Table 3). Leavers did have slightly lower high school science and math grades, and significantly higher 
verbal SAT scores. The latter suggests that they may have strengths in other fields that pulled them away from engineering.

\section{3) Involvement in Campus Activities of Stayers vs. Leavers}

A series of survey questions asked about participation in extra-curricular enrichment activities such as field trips, listening to guest speakers, work with faculty members, study groups, counseling and mentoring. Indices were created to reflect (a) participation in academic enrichment activities; (b) participation in counseling activities; (c) participation in study activities; (d) membership in student chapters of professional organizations; (e) having roommates majoring in science, math or engineering; (f) participation in non-engineering activities on campus (further detailed in the Appendix).

Leavers were less involved in engineering activities over the course of the academic year than were stayers, as might be expected (Table 4). They were less involved in academic enrichment and contact with faculty members, they participated in fewer counseling or mentoring activities and they participated in fewer study activities. They were less likely to participate in disciplinespecific engineering organization activities, or to be members of any of these organizations. Having roommates in engineering, science or math, however, did not differentiate between stayers and leavers.

Surprisingly, leavers were also less involved in non-engineering related activities, such as sports or other groups on campus. Since the leavers were more likely to be first- or second-year students, some of these differences may stem from the tendency for juniors and seniors to be more involved in these activities.

4) Engineering Self-Confidence of Stayers vs. Leavers

Indices of engineering self-confidence were created from over 30 questions about how confident the student was that he/she belongs and will stay in engineering and how competent they felt visà-vis the skills required in engineering. A factor analysis of the questions resulted in four factors, and indices were created based on the scores on these four factors: the first expressing confidence that the student belongs in and intends to stay in engineering ("Confidence in Major"); the second expressing confidence in the skills required for engineering ("Confidence in Engineering Abilities"); the third expressing confidence in general academic abilities ("Confidence in Academic Abilities"); and the fourth expressing confidence in communication skills, also needed in the engineering major ("Confidence in Communication Skills") ( see more detail in the Appendix).

Again as might be expected, leavers express less confidence that they will stay in engineering both in the fall survey and the spring survey (Table 5). Since many of the questions making up this factor relate to how well the student feels they fit in the major as opposed to other majors, this is not surprising. And the self-confidence of leavers that engineering is the right major for them decreased much more from fall to spring than did that of the stayers.

It is interesting, however, that leavers do not have less confidence in their engineering abilities and competencies than do stayers. Nor do they have less self-confidence in their overall academic ability, nor in their communication skills. Their lower self-confidence seems to be centered in their fit in the engineering niche rather than a more generalized lack of selfconfidence. 
5) Satisfaction with the Engineering Program of Stayers vs. Leavers

Satisfaction with the engineering program was measured by over 20 questions relating to various aspects of the program and interpersonal climate. A factor analysis of the questions resulted in 7 factors, for each of which a student received a factor score. The first two factors related to satisfaction with the programmatic aspects of opportunities and choice offered by the program ("Satisfaction with Program Opportunities") and the classwork load required ("Satisfaction with Coursework"). The next three factors related to satisfaction with how the program was applied: the engineering clinic set-up ("Satisfaction with Engineering Clinic"), the emphasis on teamwork ("Satisfaction with Teamwork"), and the laboratory work ("Satisfaction with Labwork"). The last two factors dealt with satisfaction with the interpersonal climate as related to fellow students ("Satisfaction with Peers") and student-faculty relations (Satisfaction with Faculty-Student Relationships) (see more detail in the Appendix).

Leavers are less satisfied than are stayers with the opportunities the program offers and the choices within the program (Table 6). However, they do not show more dissatisfaction with the course workload than stayers. Further, leavers are not less satisfied with the clinic program in general,nor with the emphasis on team or group work, nor with the laboratory work. Leavers are just about as satisfied as stayers with the faculty-student relationships and with peer relationships.

It should be noted that most of the differences in satisfaction are relatively small and are not statistically significant. This is especially important as an evaluation of the special emphases of the program: students apparently are not leaving because of the clinic program, the emphasis on team or group work, the extensive laboratory work integrated into every semester; nor are they dissatisfied with the student-faculty relationships, which Rowan faculty work so hard to achieve, and they are well integrated into the peer climate.

6) Academic Achievement of Stayers vs. Leavers

One way in which leavers significantly differ from stayers is in their GPA. Leavers have lower GPAs in both fall and spring, and report lower engineering grades as well (Table 7). It is important to recognize that this finding is mainly true for the male students leaving the program; female students do not show the same degree of difference, as we shall show below.

7) Expectations about Engineering of Stayers vs. Leavers

Students were asked ten questions about their expectations from an engineering degree. These questions were factor analyzed, and three factors resulted, for which each student was assigned a factor score. The first factor ("Social Usefulness") expressed what might be seen as the "social usefulness" expectations from a job that a degree enables. The second factor ("Personal Freedom") expressed expectations that the job would allow personal freedom. The third factor ("High Income") expressed expectations regarding the kinds of monetary rewards a job in engineering would bring(see more detail on these factors in the Appendix).

The differences between stayers and leavers were not statistically significant (Table 8), although we shall see below that there are gender differences in this respect.

8) Gender Differences in Leavers' Characteristics

There are some interesting gender differences in the comparison of stayers and leavers (Table 9). In terms of background differences, males who leave engineering had much lower math and 
science grades in high school than males who stay in engineering. They also had lower math SAT scores than males who stayed in engineering. Among females, there is hardly any difference between stayers and leavers in terms of their high school grades. And, in fact, females who leave engineering actually had a higher math SAT score than the females who stayed in engineering. This suggests that male students who leave engineering are less prepared for the kind of work they encounter; among females, however, the motivation for leaving may lie elsewhere. Among both males and females, leavers have higher verbal SAT scores than stayers, suggesting that their strengths may lie in fields other than engineering.

Both male and female leavers were less involved in engineering activities over the course of the academic year (Table 10). They were less involved in academic enrichment and contact with faculty members, and they participated in fewer counseling or mentoring activities. Female leavers were particularly uninvolved in academic enrichment or counseling activities. Both male and female leavers were less likely to participate in or be members of discipline-specific engineering organizations; however, male leavers had particularly low participation and membership in these organizations, while a third of female leavers had been members of organizations and $44 \%$ had participated in them at least occasionally. Male leavers participated in fewer study activities; female leavers, however, participated in more study-related activities than stayers. While male leavers were less active in non-engineering activities, female leavers were slightly more active in non-engineering activities than female stayers. Having roommates in science, engineering or math did not differentiate between stayers and leavers for either gender.

The picture that emerges is that female leavers are more involved in some of the engineeringrelated activities and in non-engineering activities than are male leavers. As we shall see below, female leavers do not have the same low grades as male leavers, either, and they seem to have been well integrated into the engineering culture judging from their satisfaction with peer and faculty relationships. The female leavers may be responding more to an attraction from outside of engineering rather than a push out from engineering, in contrast to the male leavers.

For both males and females, engineering self-confidence is much lower among leavers than stayers in terms of staying in engineering, and the gender difference among leavers is much greater than among stayers (Table 11). The women who leave engineering are quite sure they do not belong in engineering and that another major is better for them. This lack of engineering selfconfidence is not reflected in less confidence in their engineering abilities and competencies; in fact, among both males and females, the leavers are more confident in their engineering abilities and in their academic abilities than are the stayers. Similar patterns are found for the fall and the spring, and for both males and females, leavers lower their confidence that engineering is the right major for them more than do stayers (as would be expected). About twice the proportion of male than female leavers lower their confidence that engineering is the right major for them from fall to spring, suggesting that a higher proportion of the male leavers started out with unrealistic expectations and change a lot during the year. However, their leaving is not reflected in changed confidence regarding their mechanical abilities.

As we saw above, students who leave engineering show less satisfaction with the programmatic elements of engineering at Rowan in terms of the opportunities offered; looking at males and females separately shows us that this dissatisfaction is coming from the female leavers; male leavers do not differ from the male stayers in this respect (Table 12). 
What is even more important to note, however, is the lack of differences in satisfaction that we had expected. Previous research has suggested that women in particular leave engineering because they find the coursework too demanding, the labwork daunting, the pedagogy unsuited to their preferences, the interpersonal climate "chilly"1,7,18,21. The women who left engineering at Rowan, however, were as satisfied or more with the workload in classes, the leavers expressed even more satisfaction with teamwork and clinic than the stayers; satisfaction with labwork was not significantly different between leavers and stayers. The female leavers are as satisfied or more with faculty and peer relationships than the women who stayed in the major. Among the males there was greater dissatisfaction among leavers with regard to student-faculty relationships, but not with regard to peer relationships.

Males who leave engineering have a much lower GPA on average both in the fall and the spring, and for engineering classes in particular, than do female leavers (Table 13). In fact, female leavers appear to have even higher grades in engineering courses than do female stayers. While some of this lack of variation among females is because of less variation in grades overall among female students more generally, it also reflects something that has been found in other studies: even highly qualified female engineering students, who are doing relatively well in classes, may leave engineering; while for male students, leaving is much more closely linked to grades.

Students are not leaving engineering because they are dissatisfied with the prospects of how much money they might make in an engineering job. In fact, among females, the leavers had higher expectations of income than the stayers. Female leavers, however, were much more concerned about the lack of personal freedom an engineering job might impose (among males there is not a significant difference between leavers and stayers in this respect). Male students who leave engineering are less likely to expect to have a job that makes a social contribution. It is interesting that there is not a similar difference between female stayers and leavers. Other studies have found that for women one of the motivations for leaving engineering (and similar fields) is that they do not perceive its social usefulness or the societal context. As noted above, Rowan has integrated the social context into much of its program and particularly into the engineering clinic projects, required every semester. It is a sign of success that the women who leave engineering are not doing so because they are disillusioned with the societal contributions an engineering job will allow them to make.

That female leavers have much lower expectations regarding personal freedoms a job in engineering might afford is most likely related to their greater perception of problems for women in engineering (Table 15). Perception of problems for women in engineering was indicated by 11 survey items. To understand better the underlying dimensions of these perceptions, the eleven items were factor analyzed. Three factors emerged, reflecting three different types of problems that women are perceived to encounter. The first factor ("Societal Attitudes") deals with society's attitudes to women in science, engineering and math. The second factor ("Sem Unfeminine") deals with the view that science, engineering or math require unfeminine characteristics. The final factor ('Family-Career Conflict) dealt with the conflict between career and family: the long years of formal preparation needed, and possible conflicts between career and family responsibilities. (See detail in Appendix.)

While female leavers are actually less likely to perceive problems for women pursuing careers in SEM with regard to societal attitudes toward women in these fields or the conflict between femininity and these fields, they do perceive more problems combining career and family in 
these fields, which may be related to their lower expectations of how much freedom an engineering job would allow.

\section{Summary and Conclusions}

The research reported in this paper allows us to address a number of important questions about undergraduate retention, particularly in engineering. Rowan's undergraduate engineering program serves as kind of a natural field experiment for testing out hypotheses raised in earlier research, particularly regarding the retention of female students.

The first issue our findings address is whether Rowan's program is as female-friendly as expected to be, and whether having a program incorporating these female-friendly features impacts positively female retention in engineering without having negative repercussions for males. Since this is a program incorporating female-friendly features for all students, not targeted specifically at women, it was important to assess its impact on retention for all students, male and female; a successful inclusive model has value for all engineering programs whatever their student composition. It was therefore gratifying to find that the traditional gender gap in retention is not apparent among Rowan students. Rather, the patterns of gender differences in retention are more like what Huang \& $\mathrm{Peng}^{11}$ found for all science and engineering (S\&E) students, that is, females having better retention rates and earlier degree completion than males. As explanation for why female students seemed to do better in terms of program switching and degree completion among S\&E students, they suggested that "a very stringent selection mechanism might be at work in S\&E program entry. The selection mechanism-either by women themselves or by institutional forces or by a joint effect of both-probably filters out all but a small group of highly resilient women for S\&E programs" (p.88). It is possible that this is what is at work in Rowan's College of Engineering. That the female engineering students at Rowan have as high or higher engineering GPA's as males do ${ }^{9}$ reinforces such a conclusion.

More importantly, perhaps, are the implications that the program is indeed more "femalefriendly" than more traditional programs are. Not a program specifically targeted at women, it avoids the pitfalls of that approach (see discussion in Campbell \& $\mathrm{Hoey}^{4}$ for example), while broadening the engineering curriculum to an inclusive approach, advocated by McIntosh ${ }^{14}$ and many others. The lack of difference in family background between stayers and leavers, which we showed above, reinforces the impression of inclusivity of the program, suggesting that the Rowan program is not catering to one type of student over another.

The lack of difference between stayers and leavers in satisfaction with the applied aspects of the program - engineering clinic, teamwork, and labwork - suggests that those features most femalefriendly do not work to the disadvantage of the male students, i.e., they are as male-friendly as they are female-friendly, which is good news for any program interested in revising their curriculum to be in accordance with contemporary labor market needs in engineering (see also Rosser $^{19}$ ).

A second issue that our longitudinal research design allows us to address is whether there are early signs that a student might leave the program, even before formally withdrawing. Beginning with input characteristics of academic preparation in high school, we found that students males with lower high school achievement in math and science and lower math SAT scores were more likely to leave the program; further, both males and female leavers had higher verbal SAT scores than engineering stayers, suggesting that leavers were students with alternative strengths which they could draw upon during the undergraduate years. Our findings reinforce Astin \& Sax's ${ }^{3}$ 
finding that persistence in undergraduate science education is stronger for students with better preparation prior to the major.

Several factors reflecting experience during the undergraduate years were also related to early attrition from the program. Students with a "general" engineering major (as opposed to a more specific discipline) seemed to be more vulnerable (Rowan has subsequently discontinued the option of delaying the declaration of a specific major). That they are reflects the importance of finding a niche at the undergraduate level where the student belongs, which has been found in more general retention literature as well ${ }^{17,22}$.

Another indication that integration into a particular undergraduate niche is important is that both male and female leavers were less involved than stayers in academic enrichment and counseling activities; male leavers were also less involved than stayers in study activities and organizational activities. This underscores the importance of sense of community and integration for retention, which has been found in other engineering studies ${ }^{8,12}$ and studies of higher education in general (reviewed in Jackson et. al. ${ }^{12}$ ). It would be important to follow these students as they enter new majors, to insure that they become integrated into those programs and not marginalized in their new endeavors.

However, not all of our findings supported this explanation of retention. Both male and female leavers were as satisfied as stayers with peer and faculty relationships. Further, living with other science, math and engineering students did not have the impact on retention that has been found in other studies, particularly intentional residential communities set up for women in engineering 8,10 .

As might be expected, leavers expressed less self-confidence than stayers that they would stick with the engineering major and the career, evident even in the beginning of the academic year. However, they were not less confident in their engineering abilities, nor in their more general academic or communication abilities.

A third issue that our findings address is the role played in retention by students' expectations about their future career resulting from the major. Seymour and Hewitt ${ }^{21}$ found that women who persist in science have high intrinsic interest in science and are less materialistic and pragmatic than men in their orientation to their career; on the other hand, Rosser found that men with intrinsic occupational values were more likely to persist in science, while those with extrinsic occupational values were more likely to leave. Our indicator of expectations from a degree in engineering addressed students' reflects such values. We found that while overall expectations of what the degree in engineering will bring did not differentiate between stayers and leavers, there were differences in the relationship between expectations and persistence in the major when males and females were analyzed separately. That is, male leavers were less likely than male stayers to expect to have a job that makes a social contribution (i.e., less likely to see the social value of engineering). This would support Rosser's ${ }^{18}$ finding that men who stay in science and engineering are motivated by intrinsic rewards. However, male leavers were not more motivated by extrinsic rewards in our study.

It is interesting that we did not find that female stayers and leavers had different expectations about the social usefulness of their degree, as other studies suggest that a main reason women leave engineering is that they seek greater social usefulness in their career than engineering seems to provide ${ }^{21}$. Perhaps we can attribute the absence of this motivation to leave the program 
to Rowan's success in integrating the social context into much of its program and particularly into the engineering clinic projects.

On the other hand, female leavers are less likely to perceive the freedoms a job in engineering might bring than are female stayers. Relatedly, female leavers perceive more problems for women in the conflict between career and family than female stayers do. This suggests that a main reason for female attrition, at least at Rowan, might be alleviated were more attention given to the career-family nexus for female students, and empowering them to create niches in the engineering world that allow for more flexibility and family time. Other findings from our study have shown that women who participate in the student chapter of the Society of Women Engineers (SWE) on campus, as well as women who have had internships or employment in engineering, are less likely to perceive as problematic for women the career-family role conflict ${ }^{9}$. These then might be a mechanism by which to reduce even further female attrition from engineering at Rowan.

A follow-up study will probe in greater depth where students who leave engineering are going and why. At this point it is important to recognize that the special "female-friendly" nature of the program, which is not targeted specifically at women, does not push qualified men away nor does a chilly interpersonal climate characteristic of more traditional programs push females away.

Appendix: Indices Used in the Paper

The support index was based on answers to the following questions, asked in the fall survey: "For each of the following people, what was their opinion about your pursuit of an engineering major or career?" Possible answers were: Positive, neutral, negative. People included were: mother, father, other relative, best friend(s), boyfriend/girlfriend, most influential teacher, high school guidance counselor, someone else you knew who works in a science/math/engineering field. All of the items were recoded into dichotomies ( $1=$ Positive; $0=$ neutral or negative) and summed, for a range of $0-8$. The mean score for all males was 6.58; for all females, 6.61.

Involvement in Engineering Activities was measured by twelve items asked on the spring survey, which indicated the frequency of participation in a variety of extra-curricular activities over the course of the academic year. Responses to these items were factor analyzed using Varimax rotation. Three factors resulted: (1) The first factor indicated participation in academic enrichment activities, such as reading an engineering listserv or newsletter, hearing a guest speaker outside of class, going on an engineering field trip, working with faculty, doing research with faculty, or getting a job reference from faculty. (2) The second factor indicated participation in counseling and mentoring activities, such as meeting with an academic advisor, receiving career counseling, or receiving peer mentoring during the academic year. (3) The third factor indicated participation in study-related help activities, such as a study group, receiving or giving tutoring. Involvement in non-engineering activities was measured by four items asked on the spring survey: frequency of participation in non-engineering student organizations, an intramural or varsity sport, socializing with non-engineering students, and being a member of a fraternity or sorority. The four items were factor analyzed to provide a standardized factor score. The factor scores for each of these indices was standardized, with a mean of 0 and a range of approximately -4 to +2 . Higher scores indicated more involvement in the type of activity. 
Engineering self-confidence was measured by about 20 questions asked in the fall and repeated in the spring survey. These questions included how confident the student felt that engineering was the right major for them, how confident they were in their overall academic abilities, how competent they were in skills specific to their major (such as physics, chemistry, math, technical competence, mechanical competence). Using principal component analysis with varimax rotation, a factor analysis resulted in four factors, after items with low commonality were excluded. The first two factors related to engineering self-confidence specifically, the second two factors related to overall academic self-confidence and confidence in communication skills. The first factor reflected how confident the student was that they would stay in engineering; items with high loading on this factor included agreement that "engineering is the right major for me", how well-suited they thought they were for their college major, the likelihood that they would drop out of the major, and how well-suited they thought they were for their chosen career. The second factor reflected how confident they were in their engineering abilities, including how mechanically inclined they were, how technically inclined they were, and how good at designing they felt they were. The third factor reflected their confidence in their communication skills, including speaking, writing, and general communication. The fourth factor reflected their confidence in more general academic abilities, including overall academic ability, mathematical ability, and their interest in science compared to other students. Each factor resulted in standardized factor scores with a mean of 0and a standard deviation of 1 . The range of scores on each factor is approximately -5 to +3 ; the higher the score, the higher the self-confidence on that factor.

Satisfaction with the engineering program: The survey included over 30 questions about student's satisfaction with the engineering program, including attitudes, measured on a scale of 1-5, indicating agreement or disagreement with statements about scheduling of courses, advising, coursework load, research opportunities in the program, laboratory work, team work, the engineering clinic, faculty-student relationships and peer relationships. These items were factor analyzed, using principle-components varimax rotation, to determine the major dimensions of satisfaction with the program according to the students. Items included showed high communality (.5 or higher) and together explained at least $50 \%$ of the variance of the items. Initially three main factors were discerned, each reflecting a content area of satisfaction. Because each of the content areas encompassed many indicators, a second stage of factor analysis was performed separately on each of the content areas. The result was that the first content area, satisfaction with programmatic elements, was separated into two factors; the second content area, satisfaction with how the program was applied, was separated into three factors, and the third content area of satisfaction with interpersonal climate, was separated into two factors. The seven factors are enumerated in the text. The resulting scores on each factor are standardized, with a mean of 0 and a standard deviation of 1 . The range of scores for each factor is about -4 to +3 ; the higher the score on each factor, the higher the satisfaction.

Expectations about Engineering were indicated by ten questions asked on both the fall and spring surveys. These questions were factor analyzed, and three factors resulted. The first factor (EXPSOCUSE) expressed what might be seen as the "social usefulness" expectations from a job that an engineering degree enables. Items contributing the most to this factor included: to be respected by others, to be an important contributor to society, to get a job "where I can use my talents," and a "challenging" job. The second factor (EXPFREEDOM) expressed expectations 
that the job would allow personal freedom; items contributing the most to this factor included the expectation that a degree would allow "time to devote to interests outside my job," "a job where I will associate with interesting people," and the choice to live in any geographic location. The third factor (EXPINCOME) expressed expectations regarding the kinds of monetary rewards a job in engineering would bring: items contributing the most to this factor included that a degree would lead to a "well-paying job," "a secure job throughout my adult life," and (again) the choice "to live in any geographic location I want." As standardized scores, the mean of each of the factors was 0 and the standard deviation 1 . The scores on each factor ranged from about -3.5 to +3.0 ; the higher the score, the higher the expectations of this type.

Perception of problems for women in engineering was indicated by 11 survey items asked in the fall and again in the spring Students were asked whether they considered certain aspects of science, math and engineering (SEM) to be serious, minor or no problem for women pursuing careers in these fields. These aspects included commonly held stereotypes about women in the field, such as considering women in SEM unfeminine, women not being competitive enough, women lacking confidence in themselves; conflicts between women's more traditional roles and careers in SEM, such as the long years of preparation needed, and conflict between career and family; and lack of social support for women in these fields, including lack of encouragement from significant others, lack of career information, lack of role models, and discriminatory attitudes toward women in these fields. The eleven items were then factor analyzed, deriving three factors, which reflected three different types of problems that women are perceived to encounter. The first factor (SOCPROB) deals with society's attitudes to women in science, engineering and math: discriminatory attitudes toward women on the part of teachers or others in scientific fields generally and at Rowan in particular, lacking encouragement from teachers, counselors, family or friends. The second factor (FEMPROB) deals with the view that science, engineering or math require unfeminine characteristics: the view that women majoring in these fields are unfeminine, that women lack information about careers in the scientific field and lack female role models in scientific fields, the view that women cannot be as competitive as science classes require, and that women lack confidence that they can handle the work. The final factor (FAMPROB) dealt with the conflict between career and family: the long years of formal preparation needed, and possible conflicts between career and family responsibilities. As standardized factor scores, the mean score was 0 and the standard deviation 1 . The scores ranged from approximately -2.5 to +3 ; the higher the score, the more serious of a problem for women the issues were perceived to be.

More information on each of these indices and the actual survey instruments can be found in Hartman \& Hartman 9 .

\section{Bibliography}

[1]Adelman, C. (1998). Women and Men of the Engineering Path: A Model for Analyses of Undergraduate Careers. Washington, D.C.: U.S. Department of Education.

[2]Astin, A. W. \& Astin, H. S. (1993). Undergraduate Science Education: The Impact of Different College Environments on the Educational Pipeline in the Sciences. Los Angeles: HERI UCLA. 
[3]Astin, H.S. \& Sax, L. (1996). Developing Scientific Talent in Undergraduate Women. Ch. 4 in Davis, C., Ginorio, A., Hollinshead, C., Lazarus, B. , Rayman, P. \& associates, The Equity Equation. San Francisco: Jossey-Bass.

[4]Campbell, P. \& Hoey, L. (2003). Equity Means All: Rethinking the Role of Special Programs in Science and Math Education.

[5] Farrell, S., Kadlowec, J., Marchese, A.J., Schmalzel, J., and Mandayam, S. (2002). Hands on the Human Body: Introducing Freshmen to Multidisciplinary Engineering Principles through Application to the Human Body. ASEE Annual Meeting, Montreal, Canada.

[6]Felder, R. M., Felder, G.N., Mauney, N., Hamrin, J.C., \& Dietz, E.J., (1995). A Longitudinal Study of Engineering student Performance and Retention. III. Gender Differences in Student Performance and Attitudes. Journal of Engineering Education, 84(2), 151-174.

[7]Ginorio, A. B. (1995). Warming the Climate for Women in Academic Science. Washington, D.C.: Association of American Colleges and Universities.

[8]Goodman, I., Cunningham, C., LaChapelle, C., Thompson, M., Bittinger, K., Brennan, R. \& Delci, M., (2002). Final Report of The Women's Experiences in College Engineering (WECE) Project. Cambridge, MA: Goodman Research Group, Inc.

[9]Hartman, H. \& Hartman, M. (2004). A Gender Lens on Rowan University's College of Engineering. Final Report to NSF. Rowan University (available online at http://users.rowan.edu/ hartman).

[10]Hathaway, R. C. Davis, \& Sharp, S. (2000, May). WISE-RP Rules: Increasing Women's Retention in the Sciences. Paper presented at the Annual Forum of the Association for Institutional Research, Cincinnati, $\mathrm{OH}$.

[11]Huang, G. \& Peng, S. (2000). Entry and Persistence of Women and Minorities in College Science and Engineering Education. Research and Development Report NCES 2000-601. Washington, D.C.: National Center for Education Statistics, U.S. Department of Education, Office of Educational Research and Improvement.

[12]Jackson, L., Gardner, P. \& Sullivan, L. (1993). Engineering Persistence: Past, Present, and Future Factors and Gender Differences. Higher Education 26, 227-246.

[13]Margolis, J. \& Fisher, A. (2002). Unlocking the Clubhouse: Women in Computing. Cambridge, MA: MIT Press.

[14]McIntosh, P. (1983). Interactive Phases of Curricular Re-Vision: A Feminist Perspective. MA: Wellesley College Center for Research on Women.

[15]Meyers, C. \& Ernst, E. (1995). Restructuring Engineering Education: A Focus on Change. Report of an NSF Workshop on Engineering Education. National Science Foundation. Available at http://www.nsf.gov/pubs/stis1995/nsf9565/nsf9565.txt.

[16]Moller-Wong, C. \& Eide, A. (1997). An Engineering Student Retention Study. Journal of Engineering Education 86(1), 7-16.

[17]Pascarella, E.T. \& Terenzini, P.T. (1991).How College Affects students. San Francisco: Jossey-Bass.

[18]Rosser, Sue V. (1991). Female Friendly Science. Columbia, NY: Teacher's College Press.

[19]Rosser, SueV. (2001). Will EC2000 Make Engineering More Female Friendly? Women's Studies Quarterly 34: $164-186$.

[20]Rowan University, (2002). Resource Book 2002. Retrieved from http://www.rowan.edu/open/irp/ResBook/rbtableofcontents.html.

[21]Seymour, E. Y \& Hewitt, N. M. (1997). Talking About Leaving: Why Undergraduates Leave the Sciences. Colorado: Westview Press.

[22]Tinto, V. 1993. Leaving College: Rethinking the Causes and Cures of Student Attrition. Chicago: University of Chicago. 


\section{BIOGRAPHICAL INFORMATION}

Harriet Hartman is Professor of Sociology at Rowan University and holds a B.A. in Public Service from UCLA, M.A. in Sociology from University of Michigan, and Ph.D. in Sociology from Hebrew University of Jerusalem. She was principal investigator of the NSF research on which this paper is based. Co-author of Gender Equality and American Jews and articles in gender roles, Jewish studies. Associate Editor of Sociology of Religion.

Moshe Hartman is retired from the Department of Sociology at Ben-Gurion University. His B.A. in Statistics is from Hebrew University, M.A. and Ph.D. in Sociology from University of Michigan. Co-P.I. of NSF grant on which this paper is based. Co-authored Gender Equality and American Jews and published numerous articles in stratification, immigration and Jewish studies. 
Table 1

Engineering "Stayers" and "Leavers" who took Survey by Gender, Year in School, and Major at Time of Survey

\begin{tabular}{|c|c|c|}
\hline & Stayers & Leavers \\
\hline \multicolumn{3}{|l|}{ Gender } \\
\hline Males & 80.6 & 72.7 \\
\hline Females & 19.4 & 27.3 \\
\hline \multicolumn{3}{|l|}{ Year in School at Time of Survey } \\
\hline First-year & 27.0 & 60.6 \\
\hline Sophomore & 30.4 & 24.2 \\
\hline Junior & 24.8 & 12.1 \\
\hline Senior & 17.9 & 3.0 \\
\hline \multicolumn{3}{|l|}{ Major at Time of Survey } \\
\hline Chemical Engineering & 17.6 & 15.2 \\
\hline Civil/Environmental Engineering & 20.1 & 24.2 \\
\hline Electrical/Computing Engineering & 28.8 & 21.2 \\
\hline Mechanical Engineering & 27.3 & 24.2 \\
\hline General & 6.3 & 15.2 \\
\hline Total \% & $100.0^{*}$ & $100.0^{*}$ \\
\hline (n) & (319) & (33) \\
\hline
\end{tabular}

*Percentages rounded off to 100.0 . 
Table 2

Background Characteristics of Stayers vs. Leavers of Engineering at Rowan

\begin{tabular}{lcc}
\hline Background Characteristics & Stayers & Leavers \\
\hline Father's Education (\% no college) & 34.4 & 28.2 \\
$\begin{array}{l}\text { Mother's Education (\% no college) } \\
\text { Prestige Score of Father's Occupation }\end{array}$ & 36.9 & 28.1 \\
$\begin{array}{l}\text { Prestige Score of Mother's Occupation } \\
\text { \% Have Sibling in Science, Engineering, Math }\end{array}$ & 63.5 & 50.2 \\
$\begin{array}{l}\text { Support Index } \\
\text { N }\end{array}$ & 60.2 & 60.0 \\
\hline
\end{tabular}

Table 3

Pre-College Academic Characteristics of Stayers vs. Leavers of Engineering at Rowan

\begin{tabular}{|c|c|c|}
\hline Pre-College Academic Background Indicator: & Stayers & Leavers \\
\hline Extra-Curricular Science/Math Activities (Mean \#) & 1.4 & 1.5 \\
\hline AP Scale & 1.8 & 1.7 \\
\hline \% High School Science Grades Mostly A's & 46.8 & 34.4 \\
\hline \% High School Math Grades Mostly A's & 56.9 & 43.8 \\
\hline Verbal SAT Score* & 582 & 616 \\
\hline Math SAT Score & 649 & 643 \\
\hline
\end{tabular}

*T-test between stayers and leavers significant at $\mathrm{p}<.05$. 
Table 4

Activities at Rowan of Stayers vs. Leavers of Engineering at Rowan

(Mean Factor Scores and Percentages)

Indicators of Activities at Rowan

Stayers Leavers

ACADEMIC ACTIVITIES (Mean factor score)

.009

$-.135$

COUNSELING ACTIVITIES (Mean factor score)

.018

$-.258$

STUDY ACTIVITIES (Mean factor score)

.018

$-.255$

$\%$ member of discipline-specific engineering organization*

55.2

18.2

$\%$ participated in discipline-specific engineering organization*

67.1

30.3

$\%$ having roommates in engineering, science or math

36.0

40.0

NON-ENGINEERING ACTIVITIES (Mean factor score)

.021

$-.225$

\footnotetext{
* T-test significant at $\mathrm{p}<.05$.
} 
Table 5

Engineering Self-Confidence of Stayers vs. Leavers of Engineering at Rowan (Mean Factor Scores and Percentages)

Engineering Self-Confidence Indicator:

Stayers Leavers

(Fall)

CONFIDENCE IN MAJOR*

$.056-.564$

CONFIDENCE IN ENGINEERING ABILITIES

$-.021$

.202

CONFIDENCE IN ACADEMIC ABILITIES

$-.025$

.226

CONFIDENCE IN COMMUNICATION SKILLS

.022

(Spring)

CONFIDENCE IN MAJOR*

.075

$-.930$

CONFIDENCE IN ENGINEERING ABILITIES

$-.006$

.058

CONFIDENCE IN ACADEMIC ABILITIES

.006

$-.086$

CONFIDENCE IN COMMUNICATION SKILLS

$-.000$

Change in Engineering Self-Confidence from Fall to Spring

\% Lowered Confidence that Engineering is Right Major

19.9

27.8

\% Lowered Confidence in Mechanical Ability

23.1

16.7

\footnotetext{
*T-test significant at $\mathrm{p}<.05$.
} 
Table 6

Satisfaction with Rowan Engineering of Stayers vs. Leavers of Engineering at Rowan (Mean Factor Scores)

\begin{tabular}{lcc}
\hline Satisfaction Factor: & Stayers & Leavers \\
\hline Satisfaction with Programmatic Elements & .014 & -.224 \\
SATISFACTION WITH PROGRAM OPPORTUNITIES & -.017 & .265 \\
SATISFACTION WITH COURSEWORK & & .086 \\
Satisfaction with Applied Parts of Program & -.005 & .192 \\
SATISFACTION WITH LABWORK & -.013 & .107 \\
SATISFACTION WITH TEAMWORK & -.012 & \\
SATISFACTION WITH ENGINEERING CLINICIC & & \\
Satisfaction with Interpersonal Climate & & -.044 \\
SATISFACTION WITH FACULTY-STUDENT & .007 & .0143 \\
RELATIONSHIPS & & -.010 \\
SATISFACTION WITH PEER RELATIONSHIPS & & \\
\hline
\end{tabular}


Table 7

Academic Achievement of Stayers vs. Leavers of Engineering at Rowan (Means)

\begin{tabular}{ccc}
\hline Academic Achievement at Rowan: & Stayers & Leavers \\
\hline Fall GPA* & 3.17 & 2.20 \\
Spring GPA* & 3.18 & 2.43 \\
Engineering GPA & 3.43 & 3.26 \\
$(\mathrm{n})$ & $(319)$ & $(33)$ \\
\hline
\end{tabular}

Table 8

Expectations from Engineering Degree of Stayers vs. Leavers of Engineering at Rowan by Gender

(Mean Factor Scores)

\begin{tabular}{ccc}
\hline Factors of Expectations After Engineering Degree: & Stayers & Leavers \\
\hline SOCIAL USEFULNESS & .000 & -.025 \\
PERSONAL FREEDOM & .005 & -.121 \\
HIGH INCOME & -.006 & .159 \\
$(\mathrm{n})$ & $(294)$ & $(32)$ \\
\hline
\end{tabular}


Table 9

Pre-College Academic Characteristics of Stayers vs. Leavers of Engineering at Rowan by Gender

\begin{tabular}{|c|c|c|c|c|}
\hline Gender & & & & nales \\
\hline \multirow[t]{2}{*}{ Pre-College Academic Background Indicator: } & \multicolumn{3}{|c|}{-} & - \\
\hline & Stayers & Leavers & Stayers & Leavers \\
\hline \% High School Science Grades Mostly A’s & 45.2 & 29.2 & 53.4 & 50.0 \\
\hline \% High School Math Grades Mostly A’s & 53.5 & 27.5 & 70.7 & 62.5 \\
\hline Verbal SAT Score & 582 & 615 & 583 & 618 \\
\hline Math SAT Score & 654 & 640 & 629 & 656 \\
\hline
\end{tabular}


Table 10

Participation in Engineering-Related Activities of Stayers vs. Leavers of Engineering at Rowan by Gender

\begin{tabular}{|c|c|c|c|c|}
\hline Gender & \multicolumn{2}{|c|}{ Males } & \multicolumn{2}{|c|}{ Females } \\
\hline \multirow[t]{2}{*}{ Participation in Engineering-Related Activities: } & - & - & & \\
\hline & $\underline{\text { Stayers }}$ & $\underline{\text { Leavers }}$ & Stayers & $\underline{\text { Leavers }}$ \\
\hline ACADEMIC ACTIVITIES & -.078 & -.107 & .333 & -.182 \\
\hline COUNSELING ACTIVITIES & .026 & -.209 & -.011 & -.341 \\
\hline STUDY ACTIVITIES & -.010 & -.550 & .121 & .252 \\
\hline \multicolumn{5}{|l|}{$\%$ member of discipline-specific } \\
\hline \multicolumn{5}{|l|}{ engineering organization } \\
\hline & 52.1 & 12.5 & 67.7 & 33.3 \\
\hline \multicolumn{5}{|l|}{$\%$ participated in discipline-specific } \\
\hline \multicolumn{5}{|l|}{ engineering organization } \\
\hline & 64.2 & 25.0 & 79.0 & 44.4 \\
\hline \multicolumn{5}{|l|}{$\%$ having roommates in engineering, science } \\
\hline \multicolumn{5}{|l|}{ or math } \\
\hline & 36.7 & 40.9 & 33.3 & 37.5 \\
\hline NON-ENGINEERING ACTIVITIES & .075 & -.305 & -.170 & -.088 \\
\hline
\end{tabular}


Table 11

Engineering Self-Confidence of Stayers vs. Leavers of Engineering at Rowan (Mean Factor Scores and Percentages)

\begin{tabular}{|c|c|c|c|c|}
\hline \multirow{2}{*}{$\begin{array}{c}\text { Gender } \\
\text { Engineering Self-Confidence Indicator: }\end{array}$} & \multicolumn{2}{|r|}{ Males } & \multicolumn{2}{|c|}{ Females } \\
\hline & Stayers & Leavers & Stayers & Leavers \\
\hline \multicolumn{5}{|l|}{ Fall } \\
\hline CONFIDENCE IN MAJOR* & .088 & -.333 & -.078 & -1.256 \\
\hline CONFIDENCE IN ENGINEERING ABILITIES & .081 & .207 & -.443 & .187 \\
\hline CONFIDENCE IN ACADEMIC ABILITIES & -.049 & .155 & .074 & .440 \\
\hline CONFIDENCE IN COMMUNICATION SKILLS & .005 & -.136 & .089 & .045 \\
\hline \multicolumn{5}{|l|}{ Spring } \\
\hline CONFIDENCE IN MAJOR* & .062 & -.969 & .118 & -.858 \\
\hline CONFIDENCE IN ENGINEERING ABILITIES & .138 & .108 & -.473 & -.032 \\
\hline CONFIDENCE IN ACADEMIC ABILITIES & -.025 & -.331 & .103 & .363 \\
\hline CONFIDENCE IN COMMUNICATION SKILLS & .031 & .032 & -.101 & -.361 \\
\hline \multicolumn{5}{|l|}{ Change in Engineering Self-Confidence from Fall } \\
\hline \multicolumn{5}{|l|}{ to Spring } \\
\hline \multicolumn{5}{|l|}{$\%$ Lowered Confidence that Engineering is Right } \\
\hline Major & 21.4 & 33.3 & 10.9 & 16.7 \\
\hline$\%$ Lowered Confidence in Mechanical Ability & 25.5 & 16.7 & 14.5 & 16.7 \\
\hline
\end{tabular}


Table 12

Satisfaction with Rowan Engineering of Stayers vs. Leavers of Engineering at Rowan by Gender (Mean Factor Scores)

\begin{tabular}{|c|c|c|c|c|}
\hline & \multicolumn{2}{|c|}{ Males } & \multicolumn{2}{|c|}{ Females } \\
\hline \multicolumn{5}{|l|}{ Satisfaction Factor } \\
\hline \multicolumn{5}{|l|}{ Satisfaction with Programmatic Elements } \\
\hline SATISFACTION WITH PROGRAM OPPORTUNITIES & -.073 & -.045 & .342 & $-.507 *$ \\
\hline SATISFACTION WITH COURSEWORK & -.066 & .267 & .172 & .261 \\
\hline \multicolumn{5}{|l|}{ Satisfaction with Applied Parts of Program } \\
\hline SATISFACTION WITH LABWORK & -.032 & .128 & .095 & .018 \\
\hline SATISFACTION WITH TEAMWORK & -.073 & .048 & .205 & .440 \\
\hline SATISFACTION WITH ENGINEERING CLINIC & -.057 & .042 & .175 & .280 \\
\hline \multicolumn{5}{|l|}{ Satisfaction with Interpersonal Climate } \\
\hline FACULTY-STUDENT & & & & \\
\hline RELATIONSHIPS & .023 & -.159 & -.069 & .456 \\
\hline SATISFACTION WITH PEER RELATIONSHIPS & -.081 & -.076 & .249 & .520 \\
\hline
\end{tabular}

* T-test between stayers and leavers significant at $\mathrm{p}<.05$. 
Table 13

Academic Achievement of Stayers vs. Leavers of Engineering at Rowan by Gender (Means)

\begin{tabular}{|c|c|c|c|c|}
\hline & \multicolumn{2}{|c|}{ Males } & \multicolumn{2}{|c|}{ Females } \\
\hline Academic Achievement at Rowan: & Stayers & Leavers & Stayers & Leavers \\
\hline Fall GPA & 3.14 & $1.90^{*}$ & 3.24 & 3.11 \\
\hline Spring GPA & 3.13 & $2.25 *$ & 3.37 & 2.97 \\
\hline Engineering GPA & 3.42 & $2.98 *$ & 3.47 & 3.74 \\
\hline
\end{tabular}

*T-test between stayers and leavers significant at $\mathrm{p}<.05$.

Table 14

Expectations from Engineering Degree by Stayers vs. Leavers of Engineering at Rowan by Gender

(Mean Factor Scores)

Males

Females

\begin{tabular}{|c|c|c|c|c|}
\hline Factors of Expectations After Engineering Degree & Stayers & Leavers & Stayers & Leavers \\
\hline SOCIAL USEFULNESS & .004 & $-.031 *$ & -.015 & -.006 \\
\hline PERSONAL FREEDOM & .028 & .098 & -.044 & $-.775 *$ \\
\hline HIGH INCOME & -.055 & -.141 & .200 & 1.058 \\
\hline
\end{tabular}

* T-test between stayers and leavers significant at $\mathrm{p}<.05$. 
Table 15

Perceived Problems for Women in Science, Engineering or Math by Stayers vs. Leavers of Engineering at Rowan

(Females Only)

(Mean Factor Scores)

\begin{tabular}{lcc}
\hline $\begin{array}{l}\text { Perceived Problems for Women Pursuing Careers in Science, } \\
\text { Engineering, or Math }\end{array}$ & Stayers & Leavers \\
\hline SOCIETAL ATTITUDES & -.089 & .255 \\
SEM UNFEMININE & -.069 & .239 \\
FAMILY-CAREER CONFLICT & .027 & -.173 \\
\hline
\end{tabular}

